\title{
20
}

\section{Sustainable Development and the Red Sea-Dead Sea Canal Project}

\author{
Marc A. Rosen and Yousef Nazzal
}

Sustainability is critically important for human development. The concept of sustainable development embodies the view that social, economic and environmental objectives should be complementary and interdependent. Sustainable development requires policy changes across sectors and coherence among them, and entails balancing society's economic, social and environmental objectives, integrating them through mutually supportive policies and practices, and making appropriate tradeoffs. The Red Sea-Dead Sea Canal project (RSDSC) is an example of a megaproject that may contribute significantly to sustainable development. This chapter examines the manner in which the RSDSC contributes to the key factors for sustainability, along with the positive and negative environmental and socio-economic impacts of the project. The large amount of desalinated water expected from this project will be of great significance to partners in the region. The stratification and dilution of the Dead Sea water mass with sea water may cause losses for companies, the precipitation of gypsum, and changes in the environment of the upper water mass. The feasibility of this project must be thoroughly studied.

\subsection{Introduction}

Sustainable development was defined by the 1987 Brundtland Report of the World Commission on Environment and Development (United Nations, 1987) as "development that meets the needs of the present without compromising the ability of future generations to meet their own needs." Sustainable development has often been mistakenly interpreted as only environmental, ignoring the

Rosen, M.A. and Y. Nazzal. 2012. "Sustainable Development and the Red Sea-Dead Sea Canal Project." Journal of Water Management Modeling R245-20. doi: 10.14796/JWMM.R245-20.

(C) CHI 2012 www.chijournal.org ISSN: 2292-6062 (Formerly in On Modeling Urban Water Systems. ISBN:

978-0-9808853-7-8) 
benefit and utility of the concept in integrating economic and social development while maintaining environmental stewardship. Given its complexities, it is understandable that the concept of sustainable development is challenging to communicate (United Nations, 1987).

The concept of sustainable development embodies the view that social, economic and environmental objectives should be complementary and interdependent. Sustainable development requires policy changes across sectors and coherence among them, and entails balancing society's economic, social and environmental objectives, integrating them through mutually supportive policies and practices, and making appropriate tradeoffs.

Sustainability is studied and managed over many spatial and temporal scales and in many environmental, social and economic contexts. The focus often ranges from the Earth to economic sectors (e.g. agriculture, industry), ecosystems, countries, municipalities, neighbourhoods and individuals, and accounts for goods and services, occupations, living standards, lifestyles, behaviour patterns and suchlike. In short, sustainability can entail the full spectrum of biological and human activity or any part of it. As Daniel Botkin states, "We see a landscape that is always in flux, changing over many scales of time and space" (Homberg and Robert, 2000; Ayres, 2001).

Historically, humanity has usually responded to increasing demand for resources by increasing supply. As supplies inevitably become depleted sustainable practices are encouraged through demand management for all goods and services by promoting reduced consumption, renewable resource use, and practices that minimize resource intensity while maximizing resource productivity. Careful resource management can be applied at many scales, from economic sectors to work organizations. Careful resource management can also be applied to household and individual resource consumption patterns.

A large scale option for meeting resource demands by increasing the Dead Sea resources supply is investigated in this chapter. The Dead Sea and its unique environment are changing. The Dead Sea is a disturbed ecosystem, greatly damaged by anthropogenic intervention in its water balance. During the twentieth century, the Dead Sea level dropped by more than $25 \mathrm{~m}$ and, as of 2006, was at about $420 \mathrm{~m}$ below mean sea level (Table 20.1). Annually, the average rate of water level decline over the last decade is $1 \mathrm{~m}$, the average rate of volume decrease is $700000000 \mathrm{~m}^{3}$ and the average rate of salt accumulation at the bottom of the lake is about $0.1 \mathrm{~m} / \mathrm{y}$. Due to the high density of the Dead Sea brine, the volume decline translates to an annual freshwater deficit of about $850000000 \mathrm{~m}^{3}$. The negative water balance is mainly due to the diversion of water from its catchment area by Israel, Jordan, Syria and Lebanon, as well as industrial activity (e.g. mineral extraction) in the southern basin of the Dead 
Sea. The objective of this study is to assess the contribution of the Red SeaDead Sea canal to sustainability.

Table 20.1 Temporal variation in Dead Sea water level elevation (Beyth, 2007).

\begin{tabular}{cc}
\hline Year & Water level elevation from sea level $(\mathrm{m})$ \\
\hline 1976 & -397 \\
1982 & -401 \\
1988 & -406 \\
1994 & -408 \\
2000 & -414 \\
2006 & -419 \\
\hline
\end{tabular}

A pragmatic approach to energy sustainability, along with illustrations, is presented by Rosen (2009a; 2009b). These papers include the main criteria for achieving energy sustainability. These criteria are used in section 20.3 of this chapter, which examines how the RSDSC contributes to the key factors for sustainability, including the positive and negative environmental and socioeconomic impacts of the project.

The authors recognize that sustainability is often a vague concept and sometimes does not provide a detailed guide in terms of environmental, economic, social and other actions. Although sustainability is treated qualitatively here, to avoid overshadowing the main points with excessive details, quantitative criteria, metrics and indicators that have been developed to assess sustainability will be presented in future work.

\subsection{The Red Sea-Dead Sea Canal}

In 2002 the Red Sea-Dead Sea canal was proposed to halt the Dead Sea water level decline and deterioration of the infrastructure (Figure 20.1). The proposed project included a hydroelectric plant that will utilize the $400 \mathrm{~m}$ elevation difference between the two seas, as well as a desalination (reverse osmosis) plant to provide fresh water. In 2005, Jordan, the Palestinian Authority and Israel submitted to the World Bank terms of reference for a Feasibility StudyEnvironmental, Technical and Economic, and Environmental and Social Assessment. On 10 January 2006 the World Bank announced that steps towards the realization of the feasibility study would take place in 2007 . The project is presented not only as a project to save the Dead Sea, with potential positive implication to the sea and the stakeholders that surround it, but is also a comprehensive environmental project that will have ecological and economic benefits to all stakeholders, including those along the route of the water conveyance system, partner countries and even those north of the Dead Sea. 


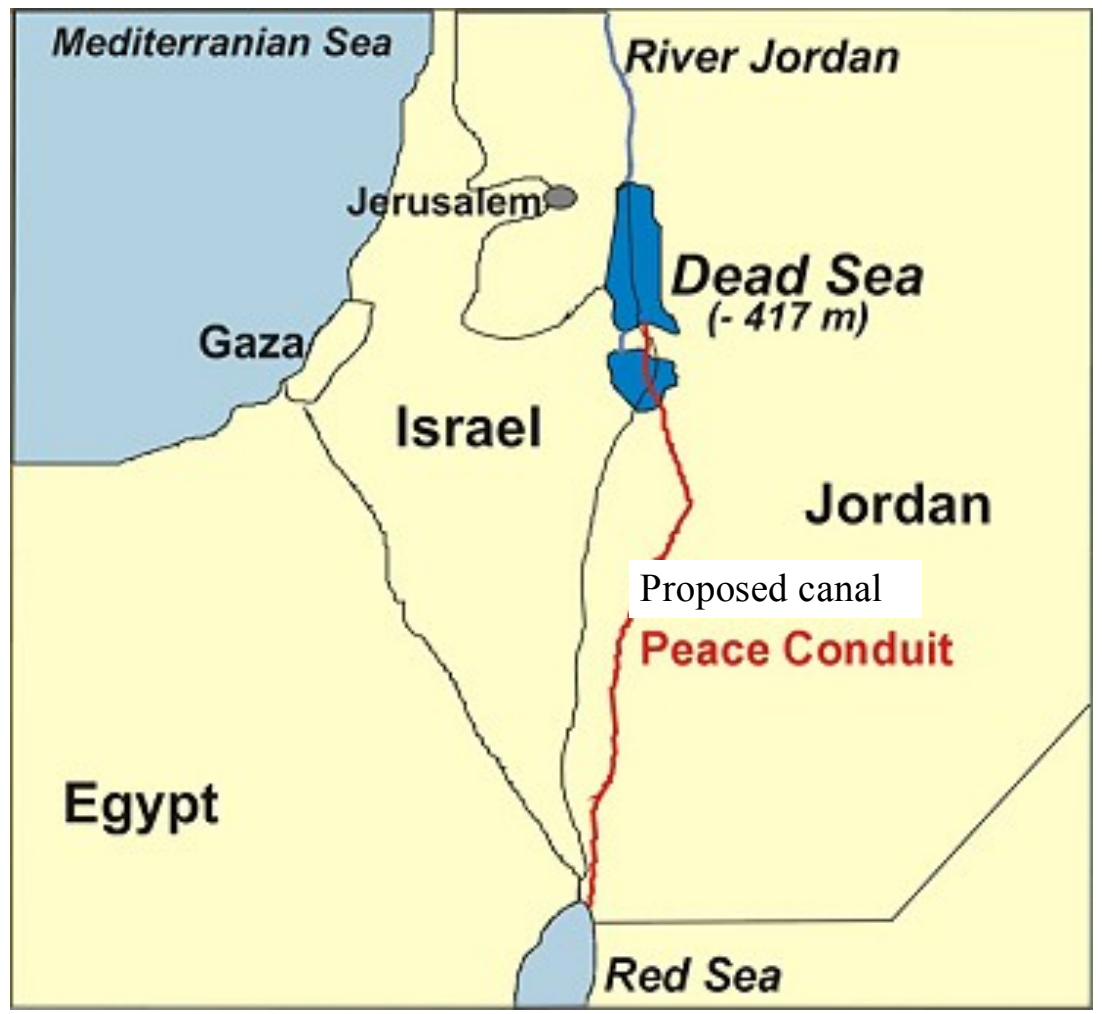

Figure 20.1 RSDSC area location (Global Nature Fund).

The Dead Sea is $377 \mathrm{~m}$ deep, the deepest hypersaline lake in the world. With $33.7 \%$ salinity, it is also one of the world's saltiest bodies of water, although Lake Assal (Djibouti), Lake Garabogazköl and some hypersaline lakes of the McMurdo Dry Valleys in Antarctica (such as Don Juan Pond) have reported higher salinities. It is 8.6 times saltier than the ocean (Goetz 1986). The salinity of the Red Sea ranges from $3.6 \%$ to $3.8 \%$. The qualitative impact of seawater mixing in the Dead Sea suggests that the inflow of seawater (or of reject brine after desalination) to the Dead Sea will have a major impact on its limnology, geochemistry and biology. During the filling stage, to a level to be decided upon by the concerned parties, the water column will become stratified with a relatively diluted upper water layer. The salinity and density of this water are difficult to predict as they will be determined by numerous parameters, such as depth of stratification, rate and timing of seawater discharge, rate of evaporation and water turbidity (Geological Survey of Israel, 2005). 


\subsubsection{Questions Raised by the Project}

The building of this water conveyance raises many questions, such as those in the following paragraph, which must be addressed to ensure the project contributes to rather than detracts from sustainability.

What impact will pumping vast quantities of seawater out of the Gulf of Aqaba have on the fragile coral reefs in this area? What changes will occur to the natural landscape of the Arava Valley during and after construction of the proposed 110 mile $(177 \mathrm{~km})$ water conveyance? What will happen when the Dead Sea is full and can no longer receive desalination brine? How will the threat posed by gypsum and microorganism growth from the mixing of Red Sea and Dead Sea waters be addressed? Will toxic odours be released as a result of the mixing of the two seas? Will control over pumping, desalinated water production, and distribution be managed by private or for profit business concerns, and how will the public interest be protected? What solutions will be found for silt and potential leakage of water during transport? Will changing the chemical composition of the Dead Sea remove its unique characteristics, especially the health benefits that lead to tourism? Will anthropogenic lakes and other infrastructure be built as part of the project in the Arava Valley? Will decisions regarding this project be made in consultation with environmental non-governmental organizations (NGOs), local communities and experts from outside relevant governments and businesses? Should the project move forward without a thorough independent assessment of possible alternatives such as the rehabilitation of the Jordan River to arrest the decline of the Dead Sea, as required by World Bank guidelines?

The concept of bringing water via a pipeline or a canal between the Red Sea and Dead Sea has been studied in many forms since the 1800s and more seriously since the mid 1900s. The Red Sea-Dead Sea water conveyance project represents a significant sustainable option for saving the Dead Sea as well as to desalinate sea water and to generate electricity.

The project is anticipated to include an intake canal at the northern tip of the Gulf of Aqaba. The water would then be pumped through either an open canal or a pipeline (about $200 \mathrm{~km}$ long) passing through Wadi Araba, Dana Natural Reserve, Ghor Al Safi and Ghor Fifa, and ending at the southern part of the Dead Sea. A desalination plant would be built near the shores of the Dead Sea and have an annual capacity of $850000000 \mathrm{~m}^{3}$ fresh water; the reject brine will be conveyed to the Dead Sea at a rate of $2600000 \mathrm{~m}^{3} / \mathrm{d}$. A hydropower generating plant would exploit the natural elevation difference between the Red Sea and the Dead Sea to provide energy for hydrostatic desalination of the Red Sea water (Royal Scientific Society of Jordan, 2007). 
The cost of this project is expected to be about $\$ 0.8$ billion for the conduit connecting the Red Sea with the Dead Sea and $\$ 3.0$ billion for the desalination project and conveyance system to demand centres funded by the World Bank. Three alignments have been considered (Beyth, 2007): the RSDSC, the QatifZikim (Qatif), and the Northern alignments.

There are six major components which are common, but having different specifications, for the three alignments as shown in Figure 20.2.

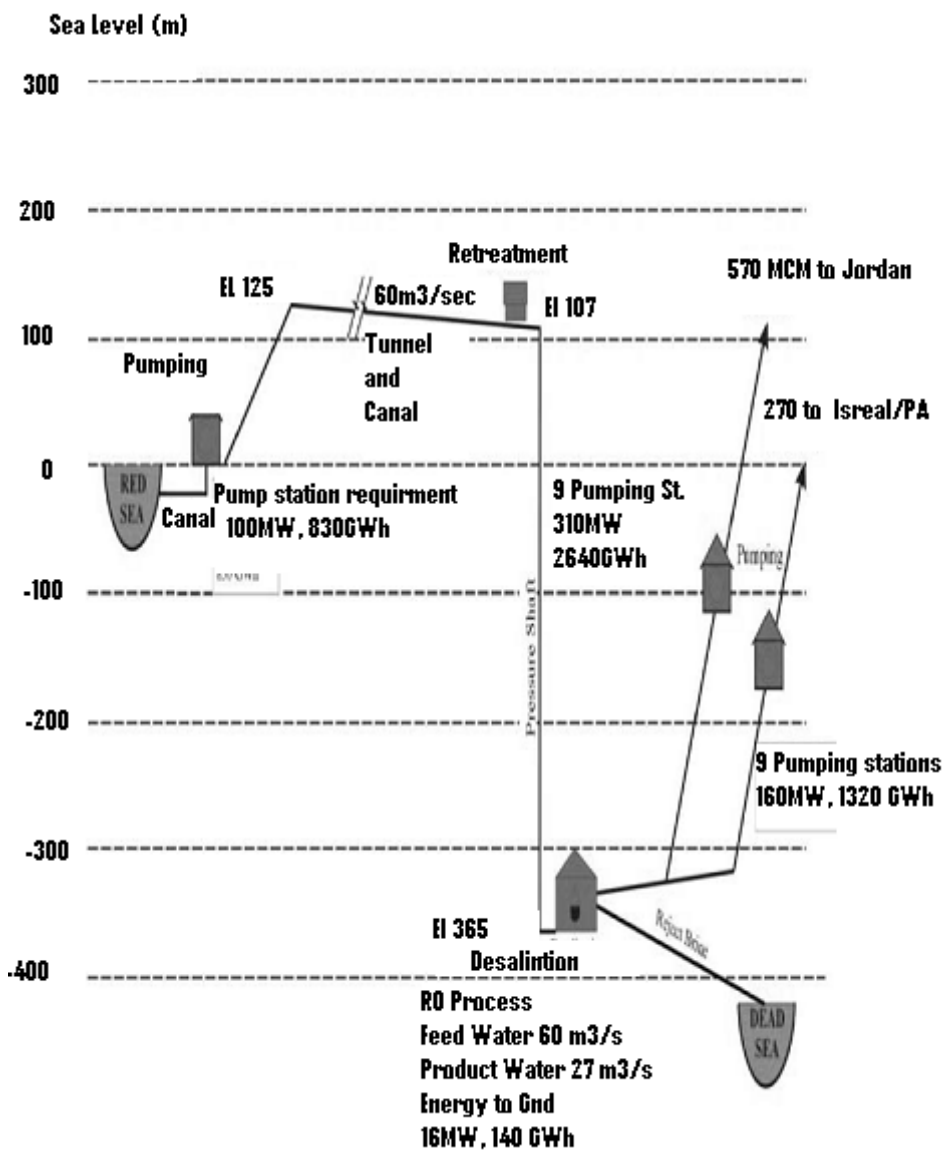

Figure 20.2 Schematic view of the RSDSC showing the elevations of project components (Beyth, 2007).

\section{Sea Intake and Pumping Station}

Seawater is pumped to $100 \mathrm{~m}$ above sea level at the Qatif alignment and to 125 $\mathrm{m}$ above sea level at the RSDSC. At the northern alignment cooling water from 
the Hadera power station is desalinated to $845 \mathrm{mg} / \mathrm{l}$ of total dissolved solids (TDS).

\section{Pressure Pipeline}

The first part of the conveyance system transports the seawater to the planned elevation. At the Qatif-Zikim alignment the length is $7.6 \mathrm{~km}$ from Qatif and at the RSDSC it is $5 \mathrm{~km}$ from Aqaba. This distance represents 3\% of the overall alignment.

\section{Canal and Tunnel}

This component is the major conveyance system. At the Qatif and RSDSC alignments seawater is transported to the regulating and pre-treatment reservoirs with a design flow rate of $60 \mathrm{~m}^{3} / \mathrm{s}$. At the Qatif alignment a $20 \mathrm{~km}$ canal and $80 \mathrm{~km}$ tunnel of $6 \mathrm{~m}$ diameter are designed, while at the RSDSC a $121 \mathrm{~m}$ tunnel of $7 \mathrm{~m}$ diameter and a $39 \mathrm{~km}$ canal is designed. At the northern alignment the partial desalinated seawater is to be transported in a short tunnel below Mt. Carmel, in pipelines of total length $80 \mathrm{~km}$.

\section{Regulating and Pretreatment Reservoirs}

At the Qatif-Zikim alignment a reservoir with a capacity of $10000000 \mathrm{~m}^{3}$ at 5 $m$ above sea level is designed at the upper basin of Nahal Parsa. At the RSDSC the reservoirs are designed to be $107 \mathrm{~m}$ above sea level at Wadi G'mal at the south-eastern margin of the Dead Sea, and at the northern alignment to be $43 \mathrm{~m}$ above sea level at Ramat Zvaiim.

\section{Desalination plant}

The desalination plants are designed to operate using the process of hydrostatically supported reverse osmosis to provide desalinated seawater. In the RSDSC, the plant will be located at Zafi, $365 \mathrm{~m}$ below sea level with a water column of $475 \mathrm{~m}$. At the Qatif alignment the plant is to be located at Nahal Parsa, about $390 \mathrm{~m}$ below sea level with a water column of $460 \mathrm{~m}$. With an annual flow rate of $2000000000 \mathrm{~m}^{3}$ and a recovery rate of $45 \%$, rejected concentrates are expected to enter the Dead Sea at an annual rate of $1100000000 \mathrm{~m}^{3}$. In the Northern alignment the plant will be located near Hamadia at an declination $258 \mathrm{~m}$ below sea level and with a water column of $300 \mathrm{~m}$.

\section{Fresh Water and Reject Brine Carriers}

In the RSDSC, two thirds of the $845000000 \mathrm{~m}^{3}$ water desalinated annually is to be provided to Amman, Jordan, and one third to the Palestinian National Authority, Hebron (Beyth, 2006); a minor amount is provided for Israel. A double pipeline $200 \mathrm{~km}$ long and $2.75 \mathrm{~m}$ in diameter is designed to convey water to Amman with nine pumping stations for an uplift of $1500 \mathrm{~m}$, while a 
double pipeline $125 \mathrm{~km}$ long with an elevation difference of $1415 \mathrm{~m}$ is designed to transmit water to Hebron.

\subsubsection{Main Goals of the RSDSC}

The RSDSC aims to avoid the loss of the Dead Sea, generate electricity, and desalinate seawater. The following major tasks have been defined, the first two by the Harza Group study (Beyth, 2006):

desalinate $2000000000 \mathrm{~m}^{3}$ seawater/year to produce $800000000 \mathrm{~m}^{3}$ to $850000000 \mathrm{~m}^{3}$ fresh water with $20 \mathrm{mg} / \mathrm{L}$ to $300 \mathrm{mg} / \mathrm{L}$ TDS;

restore the Dead Sea level to around $400 \mathrm{~m}$ below sea level. counter the accelerating degradation of the Dead Sea and the surrounding environment;

- $\quad$ supply a sustainable source of potable water for Jordan, the Palestinian National Authority and Israel; and

exploit the head difference between the Red Sea and the Dead Sea (about $400 \mathrm{~m}$ ) to produce hydroelectric power for operating the desalination plant using the process of reverse osmosis and to derive additional energy benefits.

\subsubsection{Socio-Economic Aspects of the RSDSC}

A socio-economic component study was carried out by the Water and Environmental Development Organization in cooperation with Friends of the Earth Middle East during the project period 20050701 to 200705 01, titled An environmental and socio-economic cost benefit analysis and pre-design evaluation of the proposed Red Sea-Dead Sea Canal. For the Red Sea-Dead Sea water conveyance study environmental and social assessment, an initial report was prepared by Environmental Resources Management and released in March 2010 to the World Bank. The Dead Sea's unique water composition attracts medicinal tourism, and the areas around the Dead Sea are of historical and environmental importance. The Dead Sea and its surroundings face a great challenge because of the decline in sea level.

The project area includes large and important industries for all partner countries in the project, hotels, protected areas, archaeological sites, residential areas and agricultural lands. Palestinian proposals have existed since the Oslo period in the 1990s (also known as the Oslo Accords and officially called the Declaration of Principles, which was an attempt to resolve the ongoing PalestinianIsraeli conflict) to establish Palestinian hotels on the north western shores of the Dead Sea, to create a Palestinian mineral extraction industry and to develop the many archaeological sites such as Qumrun on the West Bank areas of the Dead 
Sea. Jericho is the largest city in the Dead Sea area, located near the northwest tip of the Dead Sea. Jericho has a large agriculture and tourism economic base and prior to Israeli military closures was the gateway for tourism to the northwest shores of the Dead Sea. Ein Gedi and Ein Boqeq are the main tourism sites on the Israeli shores of the Dead Sea, with small mostly agricultural communities scattered along the length of the Araba Valley, with the Israeli port city of Eilat at the head of the Gulf of Aqaba.

Socio-economic impact studies carried out in the project area for different sectors (local residential, industry, tourism and hotels) determined that:

the majority of the surveyed sectors support the RSDSC project idea, including the majority of the Israeli, Palestinian and Jordanian populations surveyed; and

several issues need to be addressed before establishing project and during the design phase, including assessments of the need for acquisition of private land, the change of the Dead Sea water characteristics and its effect on tourism, the medical value of the project and the negative impacts of project on the marine environment in Eilat and on protected areas and archaeological sites along the proposed RSDSC route.

The majority of Israelis, Palestinians and Jordanians surveyed were interested in all options beyond the RSDSC, reflecting public interest in having all relevant information available prior to making decisions.

\subsubsection{Environmental Factors of the RSDSC}

The RSDSC has significant environmental benefits as well as challenges. One of the major motivations for the project is to compensate for the negative water balance. The targeted Dead Sea level recommended in the mid 1980s for the Qatif-Zikim alignment was $390 \mathrm{~m}$ below mean sea level (Mediterranean Dead Sea Co., 1984) and twelve years later for the RSDSC $400 \mathrm{~m}$ below mean sea level (The Harza JRV Group, 1996). Restoring the Dead Sea level is becoming increasingly important because of four hazardous phenomena resulting from its rapid level decline: the formation of more than a thousand sinkholes along the shore of the Dead Sea at the rate of 300/y (Abelson et al., 2006); the destruction of infrastructure such as roads and bridges by flood erosion; severe ecological damage to the flora and fauna around the Dead Sea; and loss of fresh groundwater due to the change of the groundwater gradient (The Harza JRV Group, 1996). Additionally, the Dead Sea level decline causes damage to the unique natural system of the Dead Sea, damage to the coral reefs of the Gulf of Aqaba due to water pumping, threats to archaeological heritage, and direct planning problems. 
Two primary options exist to overcome this drop and to create a positive water balance. One is to decrease the use of water and the loss by evaporation in chemical and other industries. The second is to import seawater through the RSDSC. Each option has benefits as well as challenges. The RSDSC option has some environmental challenges: the inflow of seawater or concentrated rejects can lead to an upper, light, stratified water body that may create a lower hypolimnion with a reduced environment (Gavrieli et al., 2005), intensive precipitation of gypsum and a change of the biological environment of the upper epilimnion water mass. This option also has geotechnical challenges (ShiravSchwartz et al., 2006), such as building a plant in a seismological active zone, the potential of water leakage, and possible contamination of the local aquifer. The northern alignment has advantages: annually diverting $200000000 \mathrm{~m}^{3}$ desalinated water to the Sea of Galilee will make the operation of the Lake of Galilee (a major fresh water reservoir) diversion possible without affecting its water quality. There is a relatively small amount of rejected concentrates in this alignment.

\subsubsection{Design of the RSDSC}

The Red Sea-Dead Sea canal represents a sustainable option which can avoid the disappearance of the Dead Sea and supply fresh water via desalination to help overcome regional deficiencies and energy option. The key project benefits include providing electricity and fresh water, preserving the Dead Sea, preventing environmental problems like sinkhole formation, improving quality of life in the project area, creating new local jobs, and enhancing regional business prosperity (including agriculture and tourism).

Concerns with the RSDSC project appear to be resolvable if caution is exercised. For instance, the canal path and structure should be designed to avoid disturbing protected areas; the ratio of Red Sea water that should be mixed with Dead Sea water to prevent chemical changes in the Dead Sea should be carefully determined utilizing appropriate tools and models; the design should incorporate appropriate measures to protect the conduit during its design and construction in fault areas; and lands should be returned to their original state before excavation, especially in agricultural and residential areas. Several measures have been recommended to address the concerns and issues:

take appropriate safety and environmental measures during canal design and construction, especially at its intersection with the fault in Arab valley and Dana area;

quantify the ratio of the Red Sea water that should be mixed with the Dead Sea water in order to prevent changes in the chemical characteristics of the Dead Sea; 
- plan and design the water conduit path and structure to avoid disturbances of protected areas;

compensate land owners fairly for destroyed trees and crops; and return lands after the project construction to their original states before excavation (including returning topsoil, removing unused soil and other wastes associated with construction), especially in agricultural and residential areas.

The project management during construction and later will be the responsibility of the partner countries, Israel, Jordan, and the Palestinian Authority.

\subsection{Potential Contributions to Sustainability}

The Red Sea-Dead Sea canal illustrates many energy-sustainability concepts (harnessing sustainable energy sources, utilizing sustainable energy carriers, increasing efficiency, reducing environmental impact and improving socioeconomic acceptability). These criteria for achieving energy sustainability are reported and examined by Rosen (2009a; 2009b), and are described as providing a pragmatic approach to energy sustainability. These criteria are used in this section. The contributions of the project to energy sustainability, in terms of these concepts, are discussed here.

\section{Sustainable Energy Sources}

The project helps improve the utilization of sustainable energy sources by generating electricity hydroelectrically, while resolving other problems. This project utilizes renewable energy, by exploiting potential energy differences which are created ultimately by solar energy.

\section{Sustainable Energy Carriers}

The energy carrier generated, electricity, is sustainable and beneficial. Using such an energy carrier for the corresponding energy demand helps enhance energy sustainability.

\section{Efficiency}

The project involves technologies that greatly improve the efficiency with which energy resources are used and other services are provided, as hydroelectric power generation is highly efficient. This high efficiency enhances the sustainability of society's energy systems. The magnitude of energy efficiency improvement that the RSDSC can bring to the region is not straightforward to determine, as it involves various countries with different energy infrastructures and utilization patterns. A first order determination of the increase in efficiency can be evaluated using a weighted mean approach. That is, the new regional 
energy efficiency can be evaluated as the energy efficiency of hydroelectric generation, multiplied by the ratio of energy used in this project to the energy used in this project and the region at present, plus the present energy efficiency of the region multiplied by the ratio of energy used in the region at present to the energy used in this project and the region at present.

\section{Environmental Impact}

The project leads to enhanced environmental performance in various ways. It generates electricity in a sustainable manner, and also addresses environmental threats to the existence of the Dead Sea. These benefits address several key aspects of reducing environmental impact related to energy (appropriate resources and carriers and efficiency), and thereby to enhance energy sustainability.

Climate change may impact the plans for hydroelectric power and the overall project, by accelerating the drying of the Dead Sea among other impacts. But if climate change becomes problematic in the region, the effects on many natural and anthropogenic systems will likely be significant and overwhelm the impacts on the RSDSC.

\section{Socioeconomic Acceptability}

Many socioeconomic benefits arise through the project. For instance, RSDSC is expected to be economically advantageous, improving some major regional industries like tourism. The project should also enhance fresh water supplies and create job opportunities. Overall, the project may contribute to more affordable energy and other services and enhanced equity. Thus the project has many socioeconomic benefits as required for energy sustainability.

\section{Discussion}

It is recognized by the authors that the concept of sustainable development is often vague and sometimes cannot provide a detailed guide for environmental protection or economic and social development. Sustainability is treated qualitatively only in the present chapter to avoid overwhelming the main points with excessive detail. Quantitative criteria, metrics and indicators have been developed to assess sustainability, and could be applied to the RSDSC. That initiative is the subject of ongoing research by the authors.

Ultimately such quantitative measures are needed to assess if a project like the one considered here truly represents a pathway for sustainable development. Economic measures usually need to be based on full cost accounting (Jerrett et al., 2003; Brauman et al., 2007; Turner et al., 2008). Nonetheless, sustainability measures are often contentious, and it is useful to employ a consensus based approach (Bender and Simonovic, 1997) to ensure agreement on the meaning of 
sustainability. In some cases, hydro-electric power development may not provide a route to sustainable development (e.g. many suggest that the hydroelectric power development in the lower Mekong Basin is not an example of sustainable development). Moreover, tradeoffs are often necessary among the competing aspects of sustainability, and it must be ensured that economics does not overwhelm other factors like social acceptability and environmental stewardship if a real contribution to sustainability is to be made by the project.

\subsection{Conclusions}

The Red Sea-Dead Sea canal has been shown to be the type of megaproject that may contribute significantly to sustainable development and, more generally, to the sustainability of human activity. The RSDSC contributes to sustainability by supporting energy sustainability, the sustainability of an important resource (fresh water), avoidance of environmental problems through the restoration of the Dead Sea, economic development and, potentially, regional political stability. The large quantities of desalinated water to be derived from the project are of particular significance to the partners in the region.

Concerns have been identified that must be addressed, such as the stratification and dilution of the Dead Sea water and changes in the biological environment of the upper water mass. Nonetheless, the project thereby addresses simultaneously social, economic and environmental objectives in a complementary and interrelated manner, and balances these societal objectives, making appropriate trade-offs as necessary.

It is demonstrated that several crucial factors required to achieve energy sustainability (harnessing sustainable energy sources, utilizing sustainable energy carriers, increasing efficiency, reducing environmental impact and improving socioeconomic acceptability) are addressed via the RSDSC project. The sustainability factors considered here can help in identifying and implementing appropriate measures, and the results are widely applicable for sustainable development.

\section{References}

Abelson, M., Yechieli, Y., Crouvi, O., Baer, G., Wachs, D., Bein A., Shtivelman, V. 2006. Evolution of the Dead Sea sinkholes, Geol. Soc. Am., 401, 241-253.

Ayres, R. 2001. Resources, Scarcity, Growth and the Environment. Report for the EU. Center for the Management of Environmental Resources, INSEAD, France.Retrieved on: 2009-04-01 from http://ec.europa.eu/environment/enveco/waste/pdf/ayres.pdf.

Bender, M.J., Simonovic, S.P. 1997.Consensus as a measure of sustainability.Hydrologic Sciences Journal, 42, 493-500. 
Beyth, M. 2006. Water crisis in Israel, in Water, Histories, Cultures, Ecologies, M. Leybourne and A. Gynor, eds, University of Western Australia Press, pp. 171-181.

Beyth, M. 2007. The Red Sea and Mediterranean-Dead Sea canal project. Desalination, 214,364-370.

Brauman, K.A., Daily, G.C., Duarte, T.K., Mooney, H.A. 2007. The nature and value of ecosystem services: An overview highlighting hydrologic services. Annual Review of Environment and Resources, 32, 67-98.

Gavrieli, I., Bein, A., Oren, A. 2005. The expected impact of the "Peace Conduit" project (the Red Sea-Dead Sea pipeline) on the Dead Sea, Mitigation and Adaptation Strategies for Global Change, 10, 3-21.

Geological Survey of Israel. 2005. Red Sea-Dead Sea water conveyance project feasibility study: Environmental and social assessment, Terms of Reference, pp. 1-43.

Goetz, P.W. 1986. The New Encyclopaedia Britannica (15th ed.). Vol. 3, p. 937. Chicago.

Holmberg, J., Robèrt, K-H. 2000. Backcasting from non-overlapping sustainability principles - a framework for strategic planning. International Journal of Sustainable Development and World Ecology, 7, 291-308.

Jerrett M., Rey, S., Dufournaud C., Jones, D. 2003. Accounting for the environmental "bottom line" along the U.S.-Mexico border. Annals of the Association of American Geographers, 93, 67-88.

Mediterranean-Dead Sea Co. 1984. Mediterranean-Dead Sea Project Planning and Prefeasibility (in Hebrew).

Rosen, M.A. 2009a. Towards energy sustainability: A quest of global proportions. Forum on Public Policy Online: A Journal of the Oxford Round Table, Summer 2008 edition, 1-20.

Rosen, M.A. 2009b. Energy sustainability: A pragmatic approach and illustrations. Sustainability, 1, 55-80.

Royal Scientific Society of Jordan. 2007. An environmental and socio-economic cost benefits analysis and pre-design evaluation of the proposal Red Sea-Dead Sea conduit, pp. 1-67.

Shirav-Schwartz, M., Calvo, R., Bein, A., Burg, A., Nof, R., Baer, G. 2006. Red SeaDead Sea conduit geoenvironmental study along the Arava Valley, Report GSI/29/2006, Geological Survey of Israel, Jerusalem.

Turner, K.R., Georgiou, S., Fisher, B. 2008. Valuing Ecosystem Services, Earthscan, Washington, D.C.

United Nations. 1987. Our Common Future, Report of the World Commission on Environment and Development.

Weiner, D. 1996. Red Sea-Dead Sea Canal Project. Draft pre-feasibility report (The Harza JRV Group in M. Beyth Group comments - RSDSC pre-feasibility draft report). 